\title{
Single Artery Upper Extremity Salvage with Two Free Flap End-to-Side Brachial Artery Anastomoses
}

\author{
Michael J. Stein, MD $^{1}$ jing Zhang, MD, PhD, FRCSC ${ }^{1}$ \\ ${ }^{1}$ Division of Plastic and Reconstructive Surgery, Department of \\ Surgery, University of Ottawa, Ottawa, Ontario, Canada \\ Address for correspondence Jing Zhang, MD, PhD, Division of Plastic \\ and Reconstructive Surgery, Department of Surgery, University of \\ Ottawa, 451 Smyth Road, Ottawa, Ontario K1H 8M5, Canada \\ J Reconstr Microsurg Open 2020;5:e57-e60. \\ (e-mail: jzhang1@toh.ca).
}

\begin{abstract}
Background A 36-year-old male was involved in a motor vehicle accident, presenting with a Guistillo's IIIB crush injury to the upper extremity. A severely comminuted ulnar fracture resulted in a 10-cm bone defect with significant overlying soft tissue injury. Methods The injury resulted in a wide zone of injury with inadequate collateral vascularity at the level of the elbow and distal viability dependent on the brachial artery. An osteocutaneous free fibular flap and fasciocutaneous anterolateral thigh flap were used to reconstruct the defect with both flaps anastomosed in an end-to-side fashion to the brachial artery.

Results The upper extremity was successfully salvaged, and the patient discharged from hospital at postoperative day 10. Both free flaps survived with no donor or

\section{Keywords}

- trauma

- upper extremity reconstruction

- end to side anastomosis

recipient site complications at a follow-up period of 2 years.

Conclusion The case illustrates the challenges inherent to significant Guistillo's IIIB injuries with insufficient recipient vessels over a large zone of injury. While performing anastomoses outside the zone of injury is preferred, this case demonstrates the success of performing multiple anastomoses to the brachial artery in an end-to-side fashion within the zone of injury.
\end{abstract}

Osteocutaneous flap reconstruction of large bony defects following Gustillo IIIB extremity trauma remains challenging. These injuries can be complicated by a large zone of injury resulting in limited recipient sites for microvascular anastomosis. Furthermore, a contaminated field and devitalized muscle and soft tissue often necessitates staged debridement to prevent osteomyelitis. The fibula remains the gold standard for vascularized reconstruction of large bone gaps due to its consistent anatomy, ample bone stock, and ability to remodel following integration. In the context of significant soft tissue damage inherent to some Gustillo IIIB injuries however, the free fibula is limited by the size and bulk of its cutaneous portion. In these cases, a second free flap is often required to resurface the soft tissue defect. Ideally, anastomoses are performed to healthy, uninjured recipient vessels outside the zone of injury.

The following case describes the salvage of a severely mangled Guistillo's IIIB upper extremity injury with inade-

received

May 3, 2020

accepted after revision

July 9,2020
DOI https://doi.org/

10.1055/s-0040-1715863. ISSN 2377-0813. quate recipient vessels for anastomosis due to the extensive zone of injury. As such, both free flaps were anastomosed in an end-to-side fashion to the brachial artery, which was the sole blood supply to the distal extremity.

\section{Case Presentation}

A 36-year-old male fell asleep at the wheel with his left arm out the window and was involved in a head-on motor vehicle collision. He presented to the trauma bay with multiple musculoskeletal injuries including left Gustillo's IIIB radius, ulna, and distal humerus fractures (-Fig. 1), as well as a left fifth metacarpal fracture, left fibula fracture, and sternal fracture. All injuries with the exception of the severe left elbow injury were deemed nonoperative and managed conservatively. His past medical history was unremarkable other than a pack per day smoking history.
Copyright $\odot 2020$ by Thieme Medical Publishers, Inc., 333 Seventh Avenue, New York, NY 10001, USA. Tel: +1(212) 760-0888.
License terms

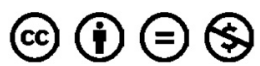




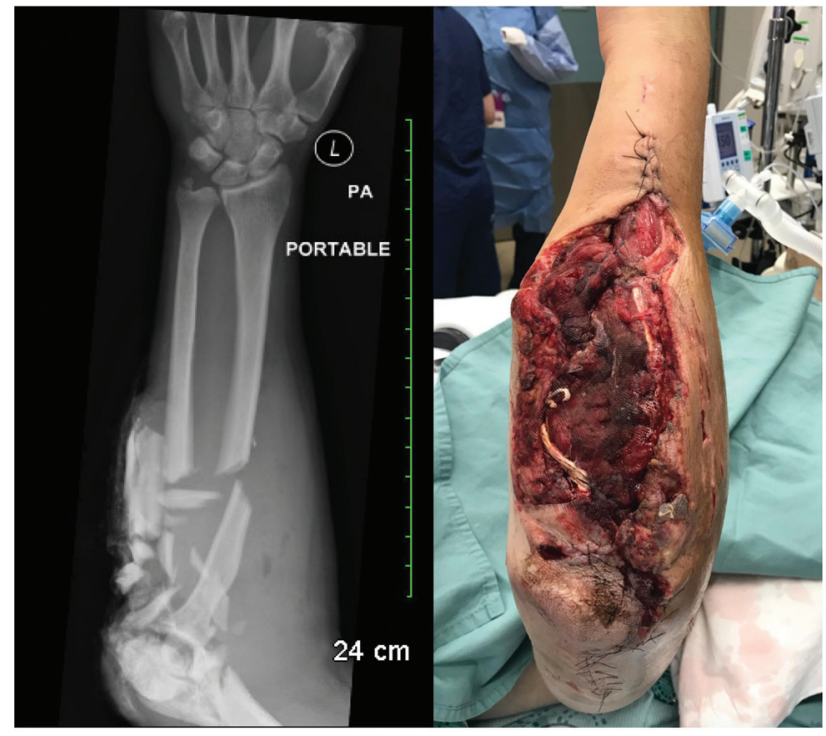

Fig. 1 (A) Left arm X-ray upon presentation to the emergency room (B) Soft tissue defect following second irrigation and debridement.

The patient underwent irrigation and debridement of his contaminated and highly comminuted left elbow fracture the day of admission and an external fixator was applied. The crush injury was noted to have a wide zone of injury with devitalized tissue requiring staged muscle and skin debridement. The comminuted proximal ulnar fragments were found to be devitalized and eventually replaced with a cement spacer as a first stage Masquelet's technique. This was followed by reduction and internal fixation of radius and humerus fractures. The large resulting soft-tissue defect was temporized with a vacuum-assisted device. The plastic surgery service was eventually consulted for soft tissue closure, as well as vascularized bone reconstruction of the $10-\mathrm{cm}$ ulna defect.

The patient was subsequently brought to the operating room for a right free fibula osteocutaneous flap and ALT fasciocutaneous flap reconstruction of the wound. Considering the extensive and circumferential zone of trauma, in addition to the lack of robust collateral flow, a decision was made to perform two end-to-side anastomoses into the brachial artery. A frank discussion with the patient preoperatively disclosed the potential for both free flap failure and subsequently upper extremity amputation.

Both ALT and free fibular flaps were elevated in an unremarkable fashion. As expected, recipient site dissection at the level of the elbow revealed no suitable collateral vessels for end-to-end anastomosis. Furthermore, clamping of the brachial artery clearly demonstrated no distal flow to the extremity. Both flaps were therefore inset within the zone of injury directly into the brachial artery in an end-toside fashion. The lateral circumflex femoral artery anastomosis was performed $2-\mathrm{cm}$ proximal to the peroneal artery anastomosis with the two venae comitantes coupled to the cephalic vein. Venous outflow from the fibular flap was supplied by a branch of the brachial vein (-Fig. 2). Clamps was then removed and vascularity restored to the distal extremity. The patient tolerated the procedure very well

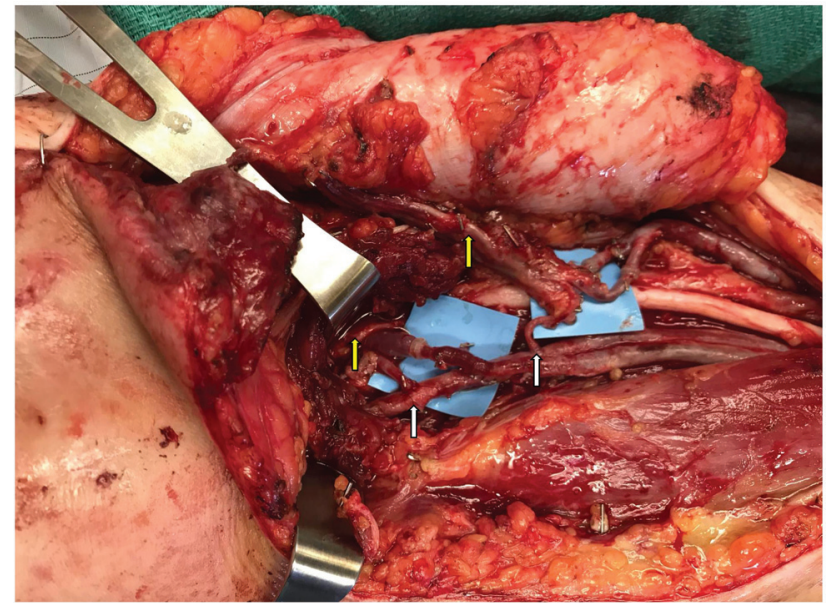

Fig. 2 Intraoperative photograph of the left upper extremity (left distal, right proximal). The left yellow arrow marks the pedicle to the fibular flap and the right yellow arrow the pedicle to the anterolateral thigh flap. The peroneal artery is anastomosed end to side into the brachial artery (left white arrow) and the associated vein was coupled end to end to a branch of the brachial vein. The descending branch of the lateral circumflex femoral artery is anastomosed end to side 2-cm proximal to the first anastomosis on the brachial artery and its two venae comitantes coupled to the cephalic vein.

and both donor and recipient sites healed with no complication (-Figs. 3 and 4). He was discharged form hospital at postoperative day 10 .

\section{Discussion}

Advances in surgical technique have led to increased limb salvage rates following severe extremity trauma. The reconstruction of these complex and often contaminated wounds usually requires temporizing external fixation and staged washouts to obtain a clean recipient site for soft tissue reconstruction. Microvascular free flaps have revolutionized

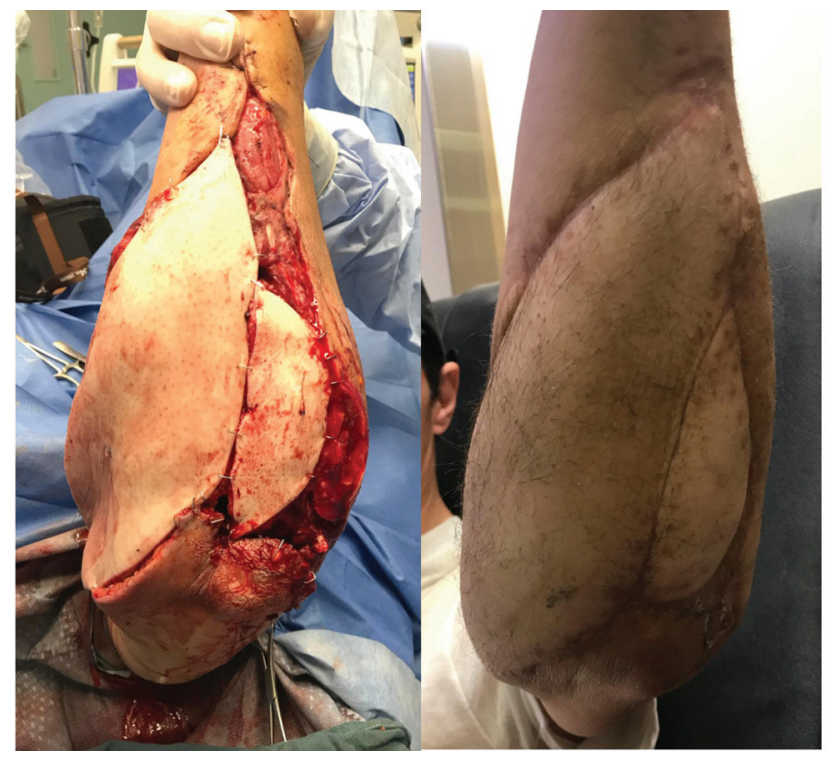

Fig. 3 (A) Intraoperative photo following fasciocutaneous ALT and osteocutaneous fibular flap reconstruction (B) Clinical photograph at 6-month postoperatively. ALT, anterolateral thigh. 


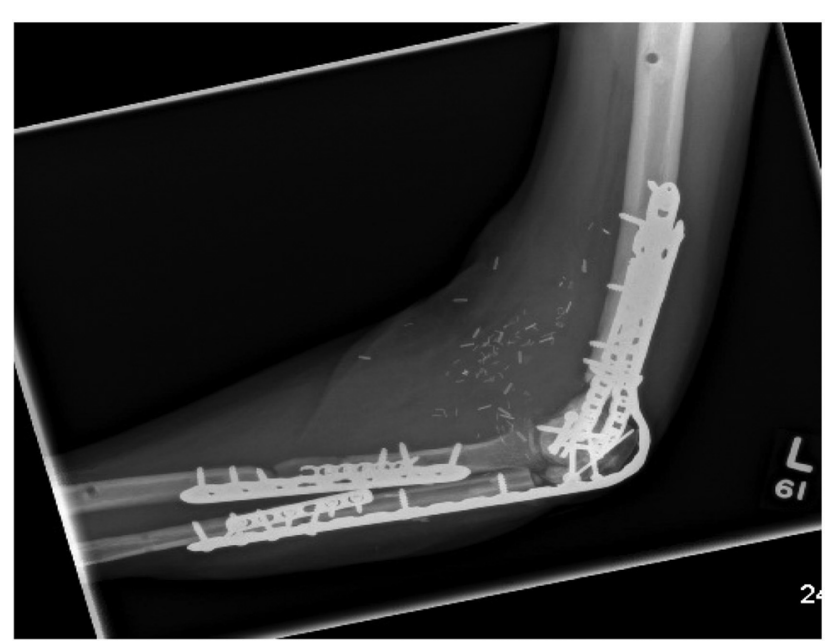

Fig. 4 X-ray following fibular and ALT flap reconstruction. ALT, anterolateral thigh.

the armamentarium for extremity reconstruction and broadened indications for limb salvage. Despite being the mainstay of lower extremity reconstruction, however, it is well known that these flaps have higher microsurgical complication rates compared with any other part of the body. ${ }^{1}$ Furthermore, the more severe the extremity trauma, the higher the rate of free flap complication. ${ }^{2}$ The timing of flap reconstruction remains controversial but is typically performed within the first two weeks of injury. ${ }^{3-6}$ Bone gap management requires either cancellous or vascularized bone grafting depending on the size of the defect. While distraction osteogenesis and Masquelet techniques ${ }^{7}$ have been used effectively for management of large boney defects, vascularized fibula flap reconstruction remains the gold standard for bone gaps over $6 \mathrm{~cm} .{ }^{8,9}$ Soft-tissue reconstruction may use either muscle or fasciocutaneous free flaps, the choice of which is largely surgeon dependent as outcomes are comparable with each. ${ }^{10}$

One of the major challenges is attaining healthy recipient vessels outside the zone of injury for anastomosis. ${ }^{11}$ It has been shown that, even in the context of a Gustillo's IIIB injury where there is no major vessel injury threatening the viability of the limb, general arterial damage in the zone of trauma itself increases the complication rate of free flap reconstruction. ${ }^{12}$ While the use of vein grafts can provide additional length to perform the anastomosis outside the zone of injury, they require further dissection, increase operating time and may even increase the risk for flap thrombosis. ${ }^{13-15}$ There is thought to be no difference in outcomes when anastomoses are performed proximal versus distal to the zone of injury. ${ }^{12,16,17}$ In the context of lower extremity trauma, two venous anastomoses are thought to be superior than one, with some authors noting a four-fold reduction in complications. ${ }^{18}$ Multiple studies have demonstrated no difference in anastomosis patency rate between end-to-end and endto-side anastomoses. ${ }^{19-21}$

The presented case illustrates the challenges plastic surgeons face in the context of a severe Guistillo's IIIB crush injury with a large bone defect. The extensive zone of trauma either requires anastomosis within the zone of injury, where there are limited recipient vessels or, alternatively, large vein grafts to reach outsize the zone of injury. Considering the known increase in flap complication rate with vein grafts and the fact that multiple long vein grafts would have been required to perform anastomoses outside the zone of injury, the authors of the present case considered end-to-side anastomoses to a single vessel arm within the zone of injury. The rationale was that the brachial artery's large caliber and high-pressure system would be less likely to be spastic and thrombose within the zone of injury compared with the small and severely traumatized collateral branches, especially considering the patient's heavy smoking history. The present case illustrates that this technique can be used safely and effectively. Having said this, these injuries continue to be approached on a case-by-case basis, paying specific attention to both patient and injury-specific factors.

Note

Written informed consent was obtained from the patient for publication of clinical details and clinical images. A copy of the consent form is available for review with the editor of the journal.

\section{Authors' Contributions}

M.J.S. and J.Z. were involved in both writing and editing the manuscript.

\section{Funding}

None.

\section{Conflicts of Interest}

None declared.

\section{References}

1 Culliford AT IV, Spector J, Blank A, Karp NS, Kasabian A, Levine JP. The fate of lower extremities with failed free flaps: a single institution's experience over 25 years. Ann Plast Surg 2007;59(01):18-21, discussion 21-22

2 Haddock NT, Weichman KE, Reformat DD, Kligman BE, Levine JP, Saadeh PB. Lower extremity arterial injury patterns and reconstructive outcomes in patients with severe lower extremity trauma: a 26-year review. J Am Coll Surg 2010;210(01):66-72

3 Lee ZH, Stranix JT, Rifkin WJ, et al. Timing of microsurgical reconstruction in lower extremity trauma: an update of the Godina paradigm. Plast Reconstr Surg 2019;144(03):759-767

4 Patterson CW, Stalder MW, Richardson W, Steele T, Wise MW, St Hilaire $\mathrm{H}$. Timing of free flaps for traumatic wounds of the lower extremity: have advances in perioperative care changed the treatment algorithm? J Reconstr Microsurg 2019;35(08):616-621

5 Kumar AR, Grewal NS, Chung TL, Bradley JP. Lessons from the modern battlefield: successful upper extremity injury reconstruction in the subacute period. J Trauma 2009;67(04):752-757

6 Rifkin WJ, Stranix JT, Borab ZM, et al. Abstract 142: timing of traumatic lower extremity free flap reconstruction: does time to coverage impact outcomes? Plast Reconstr Surg Glob Open 2018;6 (4, suppl):111-112

7 Abdou SA, Stranix JT, Daar DA, et al. Free tissue transfer with distraction osteogenesis and Masquelet technique is effective for limb salvage in patients with Gustilo type IIIB open fractures. Plast Reconstr Surg 2020;145(04):1071-1076 
8 Malizos KN, Zalavras CG, Soucacos PN, Beris AE, Urbaniak JR. Free vascularized fibular grafts for reconstruction of skeletal defects. J Am Acad Orthop Surg 2004;12(05):360-369

9 Beris AE, Lykissas MG, Korompilias AV, et al. Vascularized fibula transfer for lower limb reconstruction. Microsurgery 2011;31(03): 205-211

10 Cho EH, Shammas RL, Carney MJ, et al. Muscle versus fasciocutaneous free flaps in lower extremity traumatic reconstruction: a multicenter outcomes analysis. Plast Reconstr Surg 2018;141 (01):191-199

11 Duymaz A, Karabekmez FE, Vrtiska TJ, Mardini S, Moran SL. Free tissue transfer for lower extremity reconstruction: a study of the role of computed angiography in the planning of free tissue transfer in the posttraumatic setting. Plast Reconstr Surg 2009;124(02):523-529

12 Stranix JT, Lee ZH, Jacoby A, et al. Not all Gustilo type IIIB fractures are created equal: arterial injury impacts limb salvage outcomes. Plast Reconstr Surg 2017;140(05):1033-1041

13 Maricevich M, Lin LO, Liu J, Chang EI, Hanasono MM. Interposition Vein Grafting in Head and Neck Free Flap Reconstruction. Plast Reconstr Surg 2018;142(04):1025-1034

14 Cheng HT, Lin FY, Chang SC. Evidence-based analysis of vein graft interposition in head and neck free flap reconstruction. Plast Reconstr Surg 2012;129(05):853e-854e
15 Khouri RK, Shaw WW. Reconstruction of the lower extremity with microvascular free flaps: a 10-year experience with 304 consecutive cases. J Trauma 1989;29(08):1086-1094

16 Stranix JT, Borab ZM, Rifkin WJ, et al. Proximal versus Distal Recipient Vessels in Lower Extremity Reconstruction: A Retrospective Series and Systematic Review. J Reconstr Microsurg 2018;34(05):334-340

17 Spector JA, Levine S, Levine JP. Free tissue transfer to the lower extremity distal to the zone of injury: indications and outcomes over a 25-year experience. Plast Reconstr Surg 2007;120(04): 952-959

18 Stranix JT, Lee ZH, Anzai L, et al. Optimizing venous outflow in reconstruction of Gustilo IIIB lower extremity traumas with soft tissue free flap coverage: Are two veins better than one? Microsurgery 2018;38(07):745-751

19 Adams WP Jr, Ansari MS, Hay MT, et al. Patency of different arterial and venous end-to-side microanastomosis techniques in a rat model. Plast Reconstr Surg 2000;105(01):156-161

20 Verhelle NA, Heymans O. How to deal with difficult microsurgical end-to-side anastomoses. Microsurgery 2005;25(03):203-208

21 Dotson RJ, Bishop AT, Wood MB, Schroeder A. End-to-end versus end-to-side arterial anastomosis patency in microvascular surgery. Microsurgery 1998;18(02):125-128 